Revista Brasileira de Agricultura Irrigada v.11, nº.6, p. 1834 - 1844, 2017

ISSN 1982-7679 (On-line)

Fortaleza, CE, INOVAGRI - http://www.inovagri.org.br

DOI: $10.7127 /$ rbai.v11n600632

Protocolo 632.17 - 17/03/2017 Aprovado em 21/03/2017

\title{
PRODUÇÃO DA MAMONEIRA ‘BRS GABRIELA' SUBMETIDA A NÍVEIS DE IRRIGAÇÃO ${ }^{1}$
}

\author{
Carlos Pedro de Menezes Costa ${ }^{2}$, Hugo Orlando Carvallo Guerra ${ }^{3}$, João Henrique Zonta ${ }^{4}$, \\ Clayton Moura de Carvalho ${ }^{5}$, Paulo Gleisson Rodrigues de Sousa ${ }^{6}$, Leonaria Luna Silva de \\ Carvalho ${ }^{6}$
}

\section{RESUMO}

Embora a mamoneira seja considerada tolerante ao estresse hídrico, a sua produtividade pode ser seriamente afetada pela quantidade de água disponível no solo. Com o objetivo de avaliar a produção da mamoneira BRS Gabriela submetida a diferentes lâminas de irrigação, um ensaio experimental foi conduzido no Campo Experimental da Embrapa Algodão, no município de Barbalha, CE. Foi utilizado um delineamento experimental em blocos ao acaso, com distribuição em faixas, com 4 repetições, totalizando 24 parcelas. Os tratamentos foram distribuídos em 6 lâminas de irrigação, aplicando 150, 125, 100, 75, 50 e 25\% da evapotranspiração da cultura (ETc), estimada por Penman-Monteith. As variáveis analisadas foram: número de racemos por planta, número de frutos no racemo primário, peso de 100 sementes, teor de óleo e produtividade total. Os dados foram submetidos à análise de variância e análise de regressão. Observou-se que: a produtividade da cultura atingiu seu pico $(859,18 \mathrm{~kg}$ de sementes por hectare) quando as plantas foram irrigadas com lâmina de $81 \%$ da ETc; lâminas de 25 e $50 \%$ da ETc provocam decréscimos na produtividade, em razão do estresse por deficiência hídrica no solo, e lâminas de 100\% da ETc também provocam reduções na produtividade da mamoneira, devido aos estresses anóxiticos e hipoxíticos causados por excesso de água no solo; a mamoneira 'BRS Gabriela' é muito sensível ao excesso de água no solo, havendo morte das plantas quando são irrigadas com lâminas acima de 100\% da ETc.

Palavras-chave: produção, déficit hídrico, hipoxia, anoxia, Ricinus communis L.

\section{PRODUCTION OF CASTOR BEAN 'BRS GABRIELA' SUBMITTED AT IRRIGATION LEVELS}

\footnotetext{
${ }^{1}$ Parte da dissertação de mestrado do primeiro autor.

${ }^{2}$ Mestre em Engenharia Agrícola, Prof. do IFPI campus Oeiras, e-mail: carlos.pedromenezes@ifpi.edu.br

${ }^{3}$ PhD em Relações Água-Solo-Planta, Prof. da UFCG, e-mail: hugo@deag.ufcg.edu.br

${ }^{4}$ Doutor em Engenharia Agrícola, Pesquisador da CNPA/EMBRAPA Algodão, e-mail: zontajh@gmail.com

${ }^{5}$ Doutor em Engenharia Agrícola, Prof. do IF baiano campus Xique-xique, e-mail: carvalho_cmc@yahoo.com.br

${ }^{6}$ Mestrandos em Engenharia Agrícola, UFC, e-mails: paulo.ufc.agro@gmail.com; leonarialuna@hotmail.com
} 


\begin{abstract}
While the castor bean is considered more tolerant to water stress, your productivity can be seriously affected by the amount of available soil water. Aiming to evaluate the production of castor bean BRS Gabriela subjected to different irrigation, experimental testing was conducted at the Experimental Station of Embrapa Cotton, in the Barbalha city, Ceará. Experimental design used was randomized blocks, with distribution groups, with 4 replicates, totaling 24 plots. The treatments were distributed in 6 irrigation levels, applying 150, 125, 100, 75, 50 and 25\% of crop evapotranspiration (ETc), estimated by Penman-Monteith. The variables studied were: number of racemes per plant, number of fruits in the primary raceme, 100-seed weight, oil content and total yield. Data were subjected to analysis of variance and regression analysis. It was observed that: the yield reached its peak (859.18 kg of seeds per hectare) when plants were irrigated with blade $81 \%$ ETc; decreases in productivity because of stress due to water deficiency in the soil, and the blades 100 blades 25\% and 50\% of ETc cause ETc also cause reductions in yield of castor bean, and hipoxíticos anóxiticos due to stresses caused by excess water in the soil, the castor bean BRS Gabriela is very sensitive to excess water in the soil, with plant death when irrigated with blades up to $100 \%$ and so on.
\end{abstract}

Keywords: production, water stress, hypoxia, anoxia tolerance, Ricinus communis L.

\section{INTRODUÇÃO}

A mamoneira ((Ricinus communis L.) é uma oleaginosa com grande tolerância à seca, exigente em calor e luminosidade, adaptandose perfeitamente ao semiárido brasileiro (CARTAXO et al., 2004) e tem sido muito explorada em função do óleo contido em suas sementes que se constitui em matéria-prima para a produção do biodiesel (BELTRÃO et al., 2003).

Segundo Ramos et al., (2006), apesar da comprovada importância do óleo de mamona, o desenvolvimento da cadeia produtiva desta cultura no Brasil precisa de modernização para se tornar competitiva no programa de biodiesel. Essa modernização, segundo os autores, no tocante à fase agrícola da cadeia, passa pelo uso de técnicas mais eficientes de manejo e adoção de variedades melhoradas. De acordo com Nóbrega et al. (2001), a mamoneira apresenta ampla variabilidade genética para diversas características, este aspecto é fundamental para a implementação de programas de melhoramento específicos para esta cultura.

Entre as demandas atuais para 0 melhoramento genético da mamona, inclui-se a adaptação de genótipos à baixa altitude, o que permitirá a inclusão sustentável de muitos municípios onde o cultivo não é recomendado pelo risco de obtenção de baixas produtividades (SEVERINO et al., 2006).

Outro fator de suma importância é suprimento hídrico da planta, pois conforme Ayers e Westcot (1999), a água é o principal insumo da irrigação, seja em termos quantitativos como qualitativos. Já Marçal (2011) afirma que a grande preocupação em relação à prática agrícola nas regiões áridas e semiáridas é a qualidade da água utilizada na irrigação visto que a negligência quanto a esse aspecto produz efeitos indesejáveis na condução de culturas.

A mamoneira vem sendo explorada mundialmente, tanto em condições de sequeiro (dependente das chuvas), quanto em condições irrigadas, e apresenta média de produtividade muito baixa; isso retrata os problemas nos sistemas de cultivo utilizados em todos os países produtores. Diante dessa problemática, Beltrão (2004) afirma que a técnica da irrigação na ricinocultura se justifica caso o nível tecnológico empregado for elevado, para que se possa tirar o máximo possível de produtividade, com elevado teor de óleo de boa qualidade.

Em grande parte do território brasileiro, em especial o Nordeste, normalmente não se encontram condições naturais de precipitação 
pluvial, em quantidade e frequência suficiente para atender plenamente as necessidades hídricas das culturas, desta forma a prática da irrigação é fundamental para o bom rendimento das culturas de importância agronômica (BARRETO; AMARAL, 2004).

Sabe-se que a prática da irrigação, em geral, eleva a produtividade das culturas, porém, o que se tem observado em cultivos extensivos, como a cultura da mamoneira, é a não adoção dessa tecnologia. Já para o caso de produção de sementes, a irrigação é largamente utilizada e existem relatos de cultivos comerciais na Bahia, obtendo-se produtividades acima de $5.000 \mathrm{~kg} \mathrm{ha}{ }^{-1}$ (CARVALHO, 2005).

O uso da irrigação na agricultura e em especial na ricinocultura somente se justifica utilizando-se elevada tecnologia para se tirar o máximo possível de produtividade, com elevado teor de óleo de boa qualidade, considerando-se o teor ricinoléico que deve ser superior a $89 \%$, e a baixa acidez (BELTRÃO et al., 2004). Desta forma, escolher o sistema de irrigação mais adequado, que trará maiores produtividades com menores custos e de forma sustentável é fundamental para produção da mamona irrigada no nordeste brasileiro.

Com base no exposto o presente trabalho tem como objetivo avaliar a produção da mamoneira BRS Gabriela submetida a diferentes lâminas de irrigação com base na evapotranspiração da cultura.

\section{MATERIAL E MÉTODOS}

O experimento foi conduzido no Campo Experimental da Embrapa Algodão, no município de Barbalha - CE, localizado nas coordenadas geográficas $7^{\circ} 19^{\prime} \mathrm{S}$ de latitude, $39^{\circ} 18^{\prime} \mathrm{O}$ de longitude e 409,03 m de altitude (RAMOS et al., 2009).

O clima da região, de acordo com a classificação climática de Köppen, adaptada ao Brasil (COELHO; SONCIN, 1982), é do tipo “CSa”, semiúmido, com verão quente e seco (4 a 5 meses) e chuvas de outono e inverno. $\mathrm{O}$ período chuvoso é de março a junho e o mais seco é de outubro a dezembro. O município de Barbalha, situado a nordeste da Chapada do
Araripe possui dois tipos principais de solo: latossolo e sedimentar onde a principal elevação é a serra do Araripe (SUDENEASMIC, 1967).

Antes da instalação do experimento foi realizada coleta de amostras de solo deformadas e indeformadas, na área experimental, para determinação das características químicas e físicas.

O solo apresentou classificação textural na profundidade de 0 a $30 \mathrm{~cm}$ como franco argiloso arenoso (40\% de areia grossa, 15\% de areia fina, $12 \%$ de silte e $33 \%$ de argila), já para a profundidade de 30 a $60 \mathrm{~cm}$ foi classificada como argilo arenoso (30\% de areia grossa, $15 \%$ de areia fina, $16 \%$ de silte e $39 \%$ de argila).

No que se refere a caracterização físicohídricas o solo apresenta para a profundidade de 0 a $30 \mathrm{~cm}$ os valores de: capacidade de campo $(24,16 \%)$, ponto de murcha $(12,15 \%)$, densidade aparente $\left(1,40 \mathrm{~g} \mathrm{~cm}^{-3}\right)$ e densidade global (2,61 $\left.\mathrm{g} \mathrm{cm}^{-3}\right)$, e na profundidade de $30 \mathrm{a}$ $60 \mathrm{~cm}$ os valores de: capacidade de campo $(24,33 \%)$, ponto de murcha $(12,11 \%)$, densidade aparente $\left(1,47 \mathrm{~g} \mathrm{~cm}^{-3}\right)$ e densidade global $\left(2,58 \mathrm{~g} \mathrm{~cm}^{-3}\right)$.

O preparo do solo foi realizado com subsolagem e gradagem, sendo a calagem e adubação de fundações realizadas de acordo com a recomendação para a cultura da mamoneira em função da análise de solo. Os tratos culturais (controle de plantas invasoras, pragas e doenças, e adubação de cobertura) foram realizados de acordo com as recomendações da cultura.

A área total ocupada pelo experimento foi de $1.644 \mathrm{~m}^{2}(30 \times 54,8)$ com a área da parcela: 7,5 x 10,8 = 81,0 $\mathrm{m}^{2}$ e uma área útil de $7,0 \times 7,2=54,4 \mathrm{~m}^{2}$ com 6 fileiras duplas, 4 fileiras duplas úteis, 12 de fileiras simples e 8 fileiras simples úteis na parcela com uma área do bloco: 30,0 x 10,8 = $324 \mathrm{~m}^{2}$.

$\mathrm{O}$ delineamento experimental utilizado foi em blocos ao acaso com distribuição em faixas, com 4 repetições. As parcelas experimentais tiveram dimensão de 6 linhas de plantio com 7 metros de comprimento, sendo considerado área útil as 4 linhas centrais, e 5 metros de comprimento. 
Os tratamentos foram distribuídos em 6 lâminas de irrigação: 150, 125, 100, 75, 50 e 25\% da evapotranspiração da cultura - ETc (Figura 1). A ETc foi estimada multiplicandose a evapotranspiração de referência (ETo), obtida através do método de Penman-Monteith FAO-56, pelo coeficiente da cultura Kc (FAO
56) (ALLEN et al., 1998), com turno de rega fixo de 2 dias. Os dados meteorológicos para o cálculo da $\mathrm{ET}_{0}$ foram obtidos da Estação Meteorológica automática do Instituto Nacional de Meteorologia-INMET, localizada na região de Barbalha - CE.

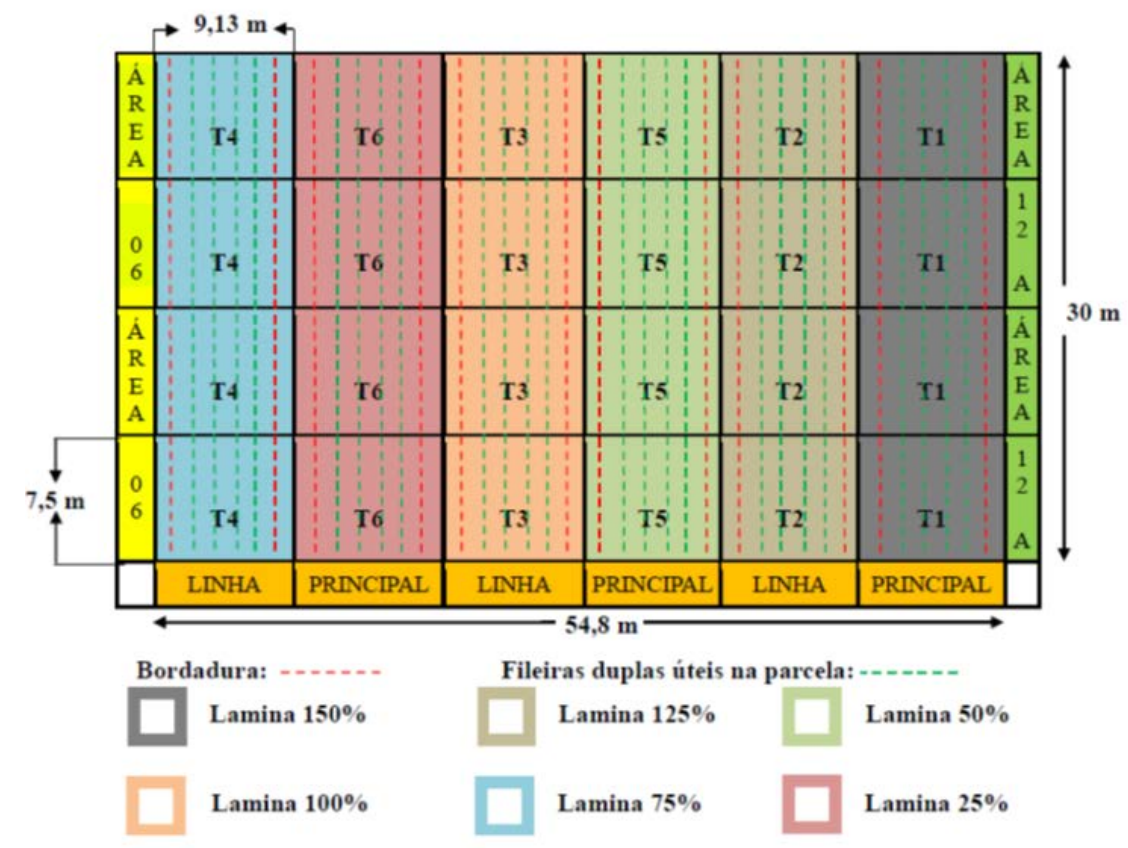

Figura 1. Croqui da área 7 no campo experimental. Barbalha, CE, 2012.

O método de irrigação adotado foi do tipo localizado, utilizou um sistema de irrigação por gotejamento, com 1 linha de gotejadores para cada fileira dupla, com gotejadores espaçados de modo a se formar uma faixa molhada. Sendo o sistema por gotejamento constituído de: conjunto motobomba de 3,0 cv; cabeçal de controle, constituído por filtro de disco, tubo de Venturi, tomada de pressão e registros; tubulações, linha principal, linha de derivação, nesta continha um cavalete com hidrômetro e válvula anti-vacúo e 36 linhas laterais, sendo uma por fileira dupla de planta; gotejadores tipo autocompensantes, modelo katif, com vazão de $2,0 \mathrm{~L} \mathrm{~h}^{-1}$ a uma pressão de serviço de $100 \mathrm{kPa}$.

A adubação baseou-se na análise química do solo e exigências nutricionais da cultura. Foi aplicado o equivalente a $33 \mathrm{~kg}$ de $\mathrm{N} \mathrm{ha}^{-1}, 150 \mathrm{~kg}$ de $\mathrm{P}_{2} \mathrm{O}_{5} \mathrm{ha}^{-1}$, tendo sido usado como fonte do nutrientes o sulfato de amônio, fosfato de monoamônio (MAP), sulfato de potássio, respectivamente. Foram distribuídos mecanizados, por ocasião da confecção dos sulcos para plantio.

A cultivar usada foi semeada diretamente no solo em covas abertas manualmente nas parcelas, sendo colocados 2 sementes por cova. A germinação deu-se a partir do $5^{\circ}$ dia após a semeadura (DAS). No $7^{\circ}$ e no $13^{\circ}$ DAS foi observado $85 \%$ e $99 \%$ de germinação. Aos 18 DAS procedeu-se o desbaste deixando 1 planta por cova.

Antes do plantio foi efetuada uma irrigação de toda a área visando elevar o teor de umidade do solo à capacidade de campo, e após o plantio, a irrigação passou a ser realizada diariamente, sendo aplicada uma pequena lâmina, de modo a garantir uma boa germinação das sementes e uniformidade de estande. Em torno de 15 dias após a germinação se iniciou a aplicação dos 
tratamentos de lâminas de irrigação, com um turno de rega de 2 dias.

A evapotranspiração da cultura (ETc) foi determinada pela seguinte equação:

$$
\mathrm{ETc}=\mathrm{ET}_{0} \mathrm{x} \mathrm{Kc}
$$

A $\mathrm{ET}_{0}$ foi determinada pelo método de Penman-Monteith parametrizado pela FAO 56 para o cálculo da evapotranspiração é expresso pela equação:

$$
E T_{0}=\frac{0,408 \Delta\left(R_{n}-G\right)+\gamma \frac{900}{T_{m e d}+273} U_{2}\left(e_{s}-e_{a}\right)}{\Delta+\gamma\left(1+0,34 U_{2}\right)}
$$

em que: ETo - Evapotranspiração de Referência, mm dia ${ }^{-1}$; Rn - Radiação líquida total do gramado, $\mathrm{MJ} \mathrm{m}^{-2}$ dia $^{-1} ; \mathrm{G}$ - Densidade do fluxo de calor no solo, $\mathrm{MJ} \mathrm{m}^{-2} \mathrm{dia}^{-1}$; Tm Temperatura média diária do ar a $2 \mathrm{~m}$ de altura, ${ }^{\circ} \mathrm{C}$; u2 - Velocidade do vento média diária a 2 $\mathrm{m}$ de altura, $\mathrm{m} \mathrm{s}^{-1}$; es - Pressão de saturação de vapor médio diário, $\mathrm{kPa}$; ea - Pressão atual de vapor médio diário, kPa; es-ea - Déficit de saturação de vapor médio diário, $\mathrm{kPa} ; \Delta$ Declividade da curva de pressão de vapor no ponto de Tm, $\mathrm{kPa}{ }^{\circ} \mathrm{C}^{-1} ; \gamma$ - Coeficiente psicrométrico, $\mathrm{kPa}^{\circ} \mathrm{C}^{-1}$.

Os valores diários do Kc utilizados foram os recomendados por FAO 56 (Allen et al., 1998).

As variáveis avaliadas foram:

- Número de racemos por planta: foi determinado por categoria: primeira, segunda e terceira ordem. Foram somados os racemos produzidos pelas plantas 2,4 , 6 e 8 da linha principal, plantas úteis, e em seguida dividido por quatro, para se obter o número médio de racemos produzidos por planta;

- Número de frutos no racemo primário: para determinação do número médio de frutos por racemo, foram contados os frutos de cada racemo primário, separadamente;

- Peso de 100 sementes: de posse das sementes beneficiadas, foram contadas aleatoriamente cem sementes e em seguida pesadas em balança digital de precisão 0,1 g. Após pesadas, acondicionadas em sacos e identificadas, as amostra de sementes, separadas por bloco, parcelas e subparcelas;

- Teor de óleo: a analise do teor de óleo foi feita pelo método de RMN de baixo Campo (Ressonância Magnética Nuclear);

- Produtividade: foi determinada através dos dados do peso de sementes por e da área ocupada pelas plantas.

Os dados obtidos foram submetidos à análise da variância pelo teste $\mathrm{F}$ a $1 \%$ e $5 \%$ de probabilidade. Quanto verificados efeitos significativos das lâminas de irrigação, os dados foram submetidos à análise de regressão, sendo selecionados os modelos que apresentaram melhores níveis de significância e coeficiente de determinação $\left(\mathrm{R}^{2}\right)$. Foi utilizado o software SISVAR 5.3 para realização das análises estatísticas.

\section{RESULTADOS E DISCUSSÃO}

As lâminas de irrigação aplicadas na mamoneira 'BRS Gabriela' durante o período experimental estão apresentadas na Tabela 1. Observa-se que, nas plantas submetidas aos níveis de 25, 50, 75, 100,125 e $150 \%$ de reposição da evapotranspiração da cultura (ETc), as lâminas totais aplicadas foram de 208,88, 341,64, 474,4, 607,16, 739,91 e 872,67 mm de água, respectivamente.

Tabela 1. Lâminas de irrigação aplicadas, em mm, nos diversos tratamentos durante o período de realização do experimento. Embrapa Algodão, Barbalha, CE, 2012.

\begin{tabular}{ccccccc}
\hline \multicolumn{7}{c}{ Lâminas de irrigação aplicadas } \\
\hline Tratamentos (\% ETc) & 25 & 50 & 75 & 100 & 125 & 150 \\
Total (mm) & 208,88 & 341,64 & 474,4 & 607,16 & 739,91 & 872,67 \\
\hline
\end{tabular}


No campo, durante a condução do experimento, as plantas que foram submetidas à irrigação baseada em 125 e 150\% da evapotranspiração da cultura, aos 50 dias após a emergência das plântulas (DAE), iniciaram um processo de murchamento e amarelamento, que levou à morte das mesmas até os $100 \mathrm{DAE}$.

Segundo Beltrão et al. (2008) a mamoneira tem baixa tolerância ao excesso de água no solo, ocorrendo alterações morfofisiológicas na planta em razão da deficiência de oxigênio no solo. De acordo com Almeida et al. (1992), a maioria das plantas glicófitas, como a mamoneira, necessita de pelo menos $10 \%$ de oxigênio na atmosfera do solo.

O solo da área experimental foi classificado, entre $0-30 \mathrm{~cm}$ de profundidade, como franco argiloso arenoso e, entre 30-60 $\mathrm{cm}$, como argilo arenoso, ou seja, possui teores relativamente altos de partículas de argila, o que aumenta a sua retenção de água, pois as forças de adsorção no solo dependem, basicamente, da espessura do filme de água que recobre as partículas, a qual varia de acordo com sua superfície específica (SILVA et al., 2005).

Através do método do infiltrômetro de anel (BRANDÃO et al., 2009), foi mensurado o valor da condutividade hidráulica do solo saturado no presente estudo, obtendo-se o valor de $0,79 \mathrm{~mm}$ hora $^{-1}$, que é considerado muito baixo, conforme adaptação de Kramer (1969), o que dificulta a capacidade de infiltração de água no solo, deixando as plantas cultivadas mais susceptíveis à estresses por excesso de água.

Dessa forma, pode-se atribuir a senescência das plantas submetidas aos maiores níveis de irrigação (125 e 150\% da ETc) à deficiência (hipoxia) ou até mesmo à ausência (anoxia) de $\mathrm{O}_{2}$ no meio edáfico (TAIZ e ZEIGER, 2013), em razão do excesso de água acumulada no solo. Dutra et al. (2012) afirmam que, em solos alagados, ocorre falta de oxigênio para as raízes, o que provoca a morte dos tecidos radiculares por favorecer a fermentação lática e acidose nas células, podendo também levar a redução na absorção de nutrientes e água por falta de energia.

Resultados semelhantes aos deste estudo foram observados por Severino et al. (2005), que concluíram que a mamoneira não sobreviveu ao encharcamento do solo por período superior a 4 dias e que os principais sintomas deste fator abiótico foram: morte da raiz pivotante; surgimento de raízes espessas e superficiais; alargamento (hipertrofia) do colo da planta formando um tecido esponjoso, seguido de necrose e morte do floema; folhas posicionando-se verticalmente e murchando a seguir; e curvamento de pecíolos foliares e do caule. Moraes e Severino (2004) e Severino et al. (2004a) verificaram que a mamoneira possui extrema sensibilidade ao estresse por anoxia (encharcamento do solo).

Em razão da senescência das mamoneiras irrigadas com lâminas de 125\% e $150 \%$ da evapotranspiração da cultura, não foi possível realizar as análises estatísticas para nenhuma das plantas correspondentes a estes tratamentos.

Conforme análise de variância (Tabela 2), constata-se que as lâminas de irrigação não afetaram de maneira significativa as seguintes variáveis: número de racemos por planta (NRAC), número de frutos no racemo primário (NFRUTRAC) peso de 100 sementes (P 100 $\mathrm{S})$, teor de óleo (TOL). Todavia, a variável produtividade (PROD) $(\mathrm{p}<0,01)$ foi afetada significativamente pelas diferentes lâminas de água, com base na evapotranspiração da cultura, de acordo com o Teste F

Tabela 2. Resumo da análise de variância para as variáveis número de racemos por planta (NRAC), número de frutos no racemo primário (NFRUTRAC) peso de 100 sementes (P 100 S_g), teor de óleo (TOL_\%) e produtividade (PROD_kg ha-1) da cultivar BRS Gabriela em função das lâminas de irrigação ao solo. Embrapa Algodão. Barbalha, CE, 2013.

\begin{tabular}{lcccccc}
\hline FV & GL & NRAC & NFRUTAC & P 100 S & TOL & PROD \\
\hline Trat & 3 & $4,54^{\text {ns }}$ & $3,52^{\text {ns }}$ & $2,13^{\text {ns }}$ & $3,69^{\text {ns }}$ & $272204,78^{* *}$
\end{tabular}


PRODUÇÃO DA MAMONEIRA 'BRS GABRIELA' SUBMETIDA A NÍVEIS DE IRRIGAÇÃO

\begin{tabular}{lcccccc} 
R. Linear & 1 & - & - & - & - & $558336,24^{* *}$ \\
R. Quadrática & 1 & - & - & - & - & $217778,55^{* *}$ \\
Desvio & 1 & - & - & - & - & $40499,55^{\mathrm{ns}}$ \\
Bloco & 3 & $0,23^{\mathrm{ns}}$ & $2,34^{\mathrm{ns}}$ & $1,10^{\mathrm{ns}}$ & $0,86^{\mathrm{ns}}$ & $8608,14^{\mathrm{ns}}$ \\
Erro & 9 & 1,89 & 2,71 & 5,01 & 2,31 & 11733,51 \\
\hline Total & 15 & \multicolumn{7}{c}{} & 53,77 & 649,65 \\
\hline MG & 5,10 & 4,18 & 47,17 & 2,83 & 16,67 \\
\hline CV (\%) & 26,93 & 39,38 & 4,75 &
\end{tabular}

Os níveis crescentes de reposição da evapotranspiração afetaram de maneira significativa a produtividade (PROD) da mamoneira 'BRS Gabriela' (Tabela 2). Observa-se, na (Figura 2), que houve melhor ajuste dos dados ao modelo polinomial quadrático, com elevado coeficiente de determinação $\left(\mathrm{R}^{2}=0,95\right)$. A produtividade da mamoneira aumentou com o incremento da lâmina até o nível de $81,0 \%$ da ETc, que propiciou uma produtividade máxima de 859,18 kg de sementes por hectare, havendo redução da variável a partir deste ponto, por outro lado, a produtividade mínima (282,7 kg $\mathrm{ha}^{-1}$ ) foi ocasionada pela menor lâmina aplicada (25\% da ETc), o que indica que tanto o déficit como o excesso de água aplicada via irrigação podem prejudicar o rendimento da mamoneira 'BRS Gabriela'.

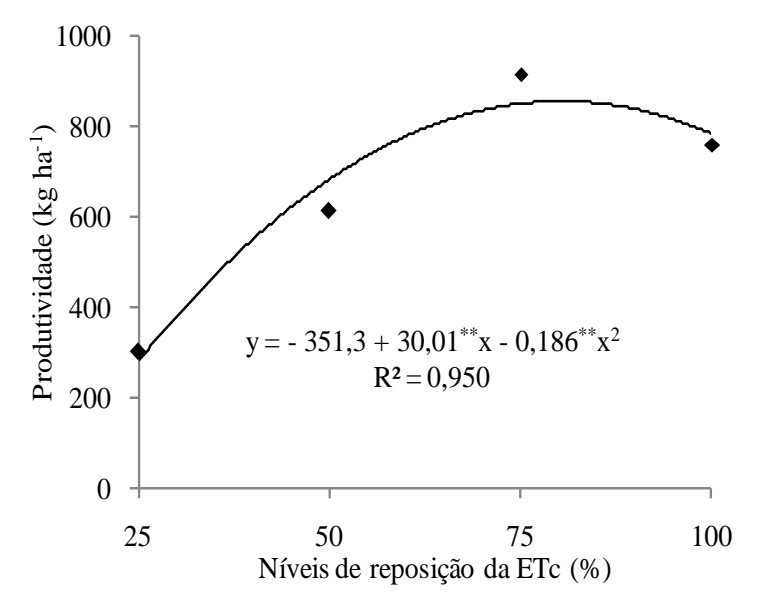

Figura 2 - Produtividade (PROD) da mamoneira, em função das diferentes lâminas de irrigação. Barbalha-CE, 2013.

Para Beltrão (2008), o prolongamento do tempo em que a planta encontra-se sob estresse poderá ocasionar redução na produtividade dos racemos de ordens mais elevadas, uma vez que parte da energia da planta está sendo utilizada para corrigir disfunções da planta.

Nas plantas submetidas às menores lâminas de irrigação, os menores valores, provavelmente, ocorreram em razão do déficit hídrico, que provoca o fechamento dos estômatos, diminuindo a fotossíntese e, consequentemente, reduzindo as atividades fisiológicas das plantas (DOBASHI et al., 1998; SCHURR et al., 2000; REGO et al., 2004; VIDAL et al., 2005), o que reflete em uma menor produtividade de sementes.

Em suma, os resultados deixam claro que, nas condições climáticas do Nordeste brasileiro, cultivos de mamoneira cultivar 'BRS Gabriela', com o uso de irrigação, têm a sua produtividade aumentada. Essas constatações estão em corroboração com Nobre (2007), na cultura da mamoneira, Silva et al. (2007), na cultura do girassol, Ramos (2002), na cultura da pupunha e Silva e Beltrão (2000), na cultura do amendoim.

Biscaro et al. (2012), estudando a produtividade das mamoneiras cv. 'IAC 80' e 'IAC 2028', observaram uma resposta quadrática significativa da produtividade das duas cultivares em função da lâmina de água aplicada, obtendo-se 1.513,9 e 1.452,4 kg de sementes por hectare, para IAC 80 e IAC 2028, respectivamente, ambas com a lâmina de $150 \%$ da evapotranspiração, havendo redução a partir daí. Os autores supracitados afirmaram que a quantidade de água aplicada, mesmo de forma suplementar, foi importante para aumentar a produtividade da cultura.

Em estudo de Moreira et al. (2009), também foi constado melhor ajuste dos dados correspondentes à produtividade de sementes da mamoneira 'IAC Guarani' ao modelo polinomial quadrático, verificando-se que o valor máximo da variável $\left(4.129,0 \mathrm{~kg} \mathrm{ha}^{-1}\right)$ foi 
obtido nas plantas irrigadas com 105,5\% de reposição da evaporação do tanque 'Classe A'. Os autores comentam que a produtividade da mamoneira tende a diminuir com a aplicação lâminas de irrigação muito elevadas, em razão de um possível excesso hídrico, que ocasiona a diminuição da pressão de oxigênio (hipoxia) ou a falta do mesmo (anoxia), dificultando a respiração das plantas e, consequentemente, diminuindo a produção de energia necessária para a síntese e translocação dos compostos orgânicos e a absorção ativa dos mesmos.

Não foi constatada significância estatística das lâminas de irrigação sobre as variáveis número de racemos por planta, número de frutos no racemo primário, peso de 100 sementes e teor de óleo, porém, os valores médios obtidos nestas variáveis estão contidos na (Tabela 3). O número médio de racemos por planta foi de 5,10; o número médio de frutos do racemo primário foi de 4,18; o peso médio de 100 sementes foi de 47,17 g; e o teor de óleo médio foi de 53,77\%.

Com relação a estas variáveis, os resultados obtidos divergem dos resultados observados por Biscaro et al. (2012), que verificaram efeito quadrático no número de racemos por planta e na massa de 100 sementes em função do aumento da lâmina de irrigação nas cultivares de mamoneira 'IAC 80' e 'IAC 2028'. Nobre (2007), estudando os efeitos de lâminas de irrigação em níveis de 25, 50, 75, $100,125 \%$ da evapotranspiração real da cultura sobre a mamoneira cv. 'IAC Guarani', constatou que o maior peso de 100 sementes foi obtido quando aplicada a lâmina de $75 \%$ da evapotranspiração, e, em seguida, os valores em peso, decresceram com o aumento das lâminas.

Moreira et al. (2009), avaliando o peso de 100 sementes dos racemos de $1^{\mathrm{a}}, 2^{\mathrm{a}}$ e $3^{\mathrm{a}}$ ordem da mamoneira cv. 'IAC Guarani', verificaram que $\mathrm{o}$ modelo polinomial quadrático foi o mais adequado, onde os valores máximos foram de 42,9 g; 43,9 g e 42,8 g para as lâminas de irrigação de 53,28; 125 e $112,3 \%$ da evaporação do tanque 'Classe A', respectivamente.

Freitas et al. (2010), estudando o número de frutos por racemo de cultivares de mamona em diferentes níveis de irrigação por gotejamento, também obtiveram resultados contrários ao obtidos no presente estudo, onde registraram aumento linear da variável na cultivar 'IAC Guarani' e efeito quadrático na 'BRS Paraguaçu'.

\section{CONCLUSÕES}

A produtividade da mamoneira 'BRS Gabriela’, nas condições edafoclimáticas do município de Barbalha/CE, atinge seu pico (859,18 kg de sementes por hectare) quando as plantas foram irrigadas com uma lâmina de irrigação correspondente a $81 \%$ da evapotranspiração da cultura.

Lâminas de irrigação baseadas em 100\% da evapotranspiração da cultura provocaram reduções na produtividade da mamoneira 'BRS Gabriela', devido aos estresses anóxiticos e hipoxíticos causados por excesso de água no solo.

Lâminas de irrigação de 25 e 50\% da evapotranspiração da cultura proporcionaram decréscimos na produtividade da mamoneira 'BRS Gabriela', em razão do estresse por deficiência hídrica no solo.

\section{REFERÊNCIAS}

ALLEN, R. G.; PEREIRA, L. S.; RAES, D.; SMITH, M. Crop evapotranspiration: guidelines for computing crop water requirements. Rome: FAO, 1998. FAO. Irrigation and Drainage Paper, 56.

ALMEIDA, O. A.; BELTRÃO, N. E. M.; CARVALHO GUERRA, H. O. Crescimento, desenvolvimento e produção de algodoeiro herbáceo em condições de anoxia do meio edáfico. Pesquisa Agropecuária Brasileira, v. 27, n. 9, p. 1259-1277, 1992.

AYERS, R. S.; WESTCOT, D. W. A qualidade de água na agricultura. 2. ed. Campina Grande: UFPB, 1999. (FAO, Irrigação e Drenagem, 29). 
BARRETO, A. N.; AMARAL, J. A. B. Quantificação de água necessária para a mamoneira irrigada com base nas constantes hídricas do solo. In: CONGRESSO BRASILEIRO DE MAMONA, 1., 2004, Campina Grande. Anais...Campina Grande: Embrapa Algodão, 2004.

BELTRÃO, N. E. M.; CARDOSO, G. D.; SEVERINO, L. S. Sistemas de produção para a cultura da mamona na agricultura familiar no semi-árido nordestino. Campina Grande: Embrapa Algodão, 2003. (Folder).

BELTRÃO, N. E. M.; CARDOSO, G. D. Informações sobre os sistemas de produção utilizados na ricinocultura na Região Nordeste, em especial o semiárido e outros aspectos ligados a sua cadeia. Campina Grande: Embrapa, 2004. (Comunicado Técnico, 213).

BELTRÃO, N. E. M.; LUCENA, A. M. A.; SILVA, G. A.; OLIVEIRA, M. I. P. Estresses hipoxítico e anoxítico em plantas de mamoneira. In: Congresso Brasileiro de Mamona, 3, 2008, Salvador. Anais... Salvador: Embrapa, 2008.

BISCARO, G. A.; VAZ, M. A. B.; GIACON, G. M.; GOMES, E. P.; SILVA, S. B.; MOTOMIYA, A. V. A. Produtividade de duas cultivares de mamona submetidas a diferentes lâminas de irrigação suplementar. Revista Brasileira de Engenharia Agrícola e Ambiental, v. 16, n. 9, p. 925-930, 2012.

BRANDÃO, V. S.; CECÍLIO, R. A.; PRUSKY, S. S.; SILVA, D. D. Infiltração da água no solo. 3. ed. Viçosa: UFV, 2009.

CARTAXO, W. V.; BELTRÃO, N. E. M.; SILVA, O. R. R. F.; SEVERINO, L. S.; SUASSUNA, N. D.; SOARES, J. J. O cultivo da mamona no semiárido brasileiro. Campina Grande: Embrapa Algodão, 2004. (Circular Técnica, 77).

CARVALHO, B. C. L. Manual do cultivo da mamona. Salvador: EBDA, 2005.
COELHO, M. A.; SONCIN, N. B. Geografia do Brasil. São Paulo: Moderna, 1982.

DOBASHI, A. M.; CARVALHO, J. A.; PEREIRA, G. M.; RODRIGUES, L. S. Avaliação do crescimento da boca de leão (Antirrihimum majus) submetido a diferentes níveis de deficiência hídrica. In: CONGRESSO BRASILEIRO DE ENGENHARIA AGRÍCOLA, 27, 1998, Poços de caldas. Anais... Poços de caldas: Sociedade Brasileira de Engenharia Agrícola, 1998.

DUTRA, C. C.; PRADO, E. A. F.; PAIM, L. R.; SCALON, S. P. Q. Desenvolvimento de plantas de girassol sob diferentes condições de fornecimento de água. Semina, v. 33, n. 1, p. 2657-2668, 2012.

FREITAS, C. A. S., BEZERRA, F. M. L.; SILVA, A. R. A.; PEREIRA FILHO, J. V.; FEITOSA, D. R. C. Comportamento de cultivares de mamona em níveis de irrigação por gotejamento em Pentecoste, CE. Revista Brasileira de Engenharia Agrícola e Ambiental, v. 14, n. 10, p. 1059-1066, 2010.

KRAMER, P. J. Plant and soil water relationships: a modern synthesis. New York: McGraw-Hill Book Company, 1969.

MARÇAL, J. A. Crescimento inicial do pinhão-manso (Jatropha curcas L.) sob irrigação com águas salinas em solo com matéria orgânica. 80 f. Dissertação (Mestrado em Agronomia) - Universidade Federal da Paraíba, Areia, 2011.

MORAES, C. R. A.; SEVERINO, L. S. Influência da saturação hídrica do solo sobre o desenvolvimento da mamoneira. In: CONGRESSO BRASILEIRO DE MAMONA, 1, 2004, Campina Grande. Anais... Campina Grande: Embrapa Algodão, 2004.

MOREIRA, L. G.; VIANA, T. V. A.; MARINHO, A. B.; NOBRE, J. G. A.; LIMA, A. D.; ALBURQUERQUE, A. H. P. Efeitos de 
diferentes lâminas de irrigação na produtividade da mamoneira variedade IAC Guarani. Revista Brasileira de Ciências Agrárias, v. 4, n. 4, p. 449-455, 2009.

NOBRE, J. G. A.; Respostas da mamona à irrigação e à aplicação de potássio em Argissolo Vermelho-Amarelo. 2007. 71 f. Dissertação (Mestrado em Engenharia Agricola) - Universidade Federal do Ceará, Fortaleza, 2007.

NÓBREGA, M. B. M.; ANDRADE, F. P.; SANTOS, J. W.; LEITE, E. J. Germoplasma, In: AZEVEDO, D. M. P.; LIMA, E. F. (edd.) O agronegócio da mamona no Brasil. Brasília: Embrapa Algodão, 2001. p. 257-281.

RAMOS, A. M.; SANTOS, L. A. R.; FORTES, L. T. G. Normais climatológicas do Brasil. Brasília: INMET, 2009.

RAMOS, A.; Analise do desenvolvimento vegetativo e produtividade da palmeira pupunha (Bractris gasípaes kunth) sob lâminas de irrigação e adubação nitrogenada. 113 f. Tese (Doutorado em Agronomia) - Escola Superior de Agricultura Luiz de Queiroz, Piracicaba, 2002.

RAMOS, N. P.; AMORIM, E. P.; SAVY FILHO, A. Potencial da cultura da mamona como fonte de matéria-prima para o programa nacional de produção e uso de biodiesel. In: Câmara, G. M. S.; HEIFFIG, L. S. (coords.). Agronegócio de plantas oleaginosas: matérias-primas para biodiesel. Piracicaba: ESALQ, 2006. p.81-104.

REGO, J. L.; VIANA, T. V. A.; AZEVEDO, B. M.; BASTOS, F. G. C.; GONDIM, R. S. Efeitos de níveis de irrigação sobre a cultura do crisântemo. Revista Ciência Agronômica, v. 35, n. 2, p.3 02-308, 2004.

SCHURR, U.; HECKENBERGER, U.; HERDEL, K.; WATER, A.; FEIL, R. Leaf development in Ricinus communis during drought stress: dynamics of growth processes, of cellular structure and of sink-source transition. Journal of experimental Botany, v. 51, n. 350, p. 1515-1529, 2000.

SEVERINO, L. S.; LIMA, C, L, D.; BELTRÃO, N. E. M.; CARDOSO, G. D.; FARIAS, V, A. Comportamento da mamoneira sob encharcamento do solo. Campina Grande: Embrapa, 2005. (Boletim de Pesquisa e desenvolvimento, 57).

SEVERINO, L. S.; LIMA, C. L. D.; BELTRÃO, N. E. M.; CARDOSO, G. D.; FARIAS, V. A. Mamoneira submetida a encharcamento do solo. In: CONGRESSO BRASILEIRO DE MAMONA, 1, 2004, Campina Grande. Anais... Campina Grande: Embrapa Algodão, 2004.

SEVERINO, L. S; MILANI, M; MORAES, C. R. de A; GONDIM, T. M. de S; E CARDOSO, G. D. Avaliação da produtividade e teor de óleo de dez genótipos de mamoneira cultivados em altitude inferior a 300 metros. Ciência Agronômica, v. 37, n. 2, p. 188-194, 2006.

SILVA, L. C.; BELTRÃO, N. E. M.; incremento de fitomassa e produtividade do amendoinzeiro em função de lâmina e intervalos de irrigação. Revista Brasileira de Oleaginosas e Fibrosas, v. 4, n. 2, p. 111-121, 2000.

SILVA, M. A. S.; MAFRA, A. L.; ALBUQUERQUE, J. A.; BAYER, C.; MIELNICZUK, J. Atributos físicos do solo relacionados ao armazenamento de água em um Argissolo Vermelho sob diferentes sistemas de preparo. Ciência Rural, v. 35, n. 3, p. 544-552, 2005.

SILVA, M. L. O.; FARIA, M. A.; REIS, R. P.; SANTANA, $\quad$ M. J.; MATTIOLI,W.; viabilidade técnica e economica do cultivo de safrinha do girassol irrigado na Região de Lavras, MG. Ciência agrotécnica, v. 31, n. 1, p. 200-205, 2007.

SUDENE-ASMIC. Estudo geral de base do vale do Rio Jaguaribe. v. IV. Hidrologia. Brasília: GVJ, 1967. 
PRODUÇÃO DA MAMONEIRA 'BRS GABRIELA’ SUBMETIDA A NÍVEIS DE IRRIGAÇÃO

TAIZ, L.; ZEIGER, E. Fisiologia vegetal. 5. ed. Porto Alegre: Artmed, 2013.

VIDAL, M. S.; CARVALHO, J. M. F. C.;
MENESES, C. H. S. G. Déficit Hídrico: aspectos morfofisiológicos. Campina Grande: Embrapa Algodão, 2005. (Documentos, 142). 